\title{
GAIA Level 1 Placental Abruption
}

National Cancer Institute

\section{Source}

National Cancer Institute. GAIA Level 1 Placental Abruption. NCI Thesaurus. Code C128748.

GAIA Level 1 Placental Abruption is defined by two criteria: first, vaginal bleeding during the second or third trimester in the absence of placenta previa on ultrasound; second, one of the following two requirements must be met: a) Uterine irritability (irregular, frequent uterine activity, not coalesced into clear contractions in a regular pattern) or labor; OR b) Clinical signs of hypovolemic shock or coagulopathy. Alternatively, Level 1 may be defined as placental pathology with histologic findings of a chronic abruption. 